\title{
High HbA1c at onset cannot be used as a predictor for future metabolic control for the individual child with type 1 diabetes mellitus
}

J ohn Nilsson, Karin Åkesson, Lena Hanberger and Ulf Samuelsson

The self-archived postprint version of this journal article is available at Linköping University Institutional Repository (DiVA):

http:// urn.kb.se/ resolve?urn=urn:nbn:se:liu:diva-143232

N.B.: When citing this work, cite the original publication.

Nilsson, J., Ákesson, K., Hanberger, L., Samuelsson, U., (2017), High HbA1c at onset cannot be used as a predictor for future metabolic control for the individual child with type 1 diabetes mellitus, Pediatric Diabetes, 18(8), 848-852. https:// doi.org/ 10.1111/pedi.12498

Original publication available at:

https:// doi.org/ 10.1111/pedi.12498

Copyright: Wiley (12 months)

http:// eu.wiley.com/WileyCDA/ 


\section{Metabolic control at onset and follow-up}

John Nilsson

Department of Paediatrics, Ryhov County Hospital

55185 Jönköping

Sweden

Tel: +4636322256

Fax: +4636322234

E-mail: john.nilsson@rjl.se 


\section{High HbA1c at onset cannot be used as a predictor for \\ future metabolic control for the individual child with type}

\section{1 diabetes mellitus}

John Nilsson $\mathrm{MD}^{1}$

Karin Åkesson MD, $\mathrm{PhD}^{1,2}$

Lena Hanberger RN, $\mathrm{PhD}^{3}$

Ulf Samuelsson MD, PhD, Ass Prof ${ }^{4}$

${ }^{1}$ Department of Paediatrics, Ryhov County Hospital, Jönköping, Sweden

${ }^{2}$ Futurum - Academy for Health and Care, Jönköping County Council and Jönköping

Academy for improvement of Health and Welfare, Jönköping University, Jönköping, Sweden

${ }^{3}$ Department of Medicine and Health Sciences, Division of Nursing, Linköping University, Linköping, Sweden

${ }^{4}$ Department of Clinical and Experimental Medicine, Division of Paediatrics and Diabetes Research Centre, Linköping University Hospital, Linköping, Sweden

Word count: 3875 


\section{Abstract}

Objectives: To study how metabolic control at onset of type 1 diabetes correlates to metabolic control and clinical parameters during childhood until transition from paediatric care to adult diabetes care.

Methods: Data at onset, three months, one, three, and five years after diagnosis and at transition, on HbA1c and clinical parameters, on 8084 patients in the Swedish paediatric quality registry, SWEDIABKIDS, were used. Of these patients, $26 \%$ had been referred to adult diabetes care by 2014 .

Results: Children with HbA1c $<72 \mathrm{mmol} / \mathrm{mol}$ (8.7 \%) (20 \% of patients, low group) at diagnosis continued to have good metabolic control during childhood, in contrast to children with $\mathrm{HbA1c}>114 \mathrm{mmol} / \mathrm{mol}$ (12.6 \%) (20\% of patients, high group) at diagnosis, who continued to have high HbA1c at follow-up. For the individual, there was no significant correlation between high HbA1c at onset and during follow-up. During follow-up, children in the high group were more often smokers, less physically active, and more often had retinopathy than children in the low group ( $\mathrm{p}=0.003,0.001,0.028$ respectively).

Conclusion: High HbA1c at onset was associated with high HbA1c during follow-up on a group level, but it cannot be used as a predictor of future metabolic control on an individual level. These results emphasize the important work done by the diabetes team in the first years after diagnosis. It is important to continuously set high goals for the achievement of tight metabolic control, in order to decrease the risk of microvascular complications.

Key words: Diabetes Mellitus, Type 1- children - HbA1c- quality registry 


\section{Introduction}

Type 1 diabetes mellitus (T1D) is the second most common chronic disease in children and adolescents. Intensive therapy of patients with T1D delays the onset of long-term complications and slows the progression of complications (1-4). Intensive treatment improves metabolic control, measured as HbA1c (glycated haemoglobin), which reflects the mean glycaemic level during the preceding two to three months (5). Frequent self-monitoring of blood glucose (SMBG) is also important in order to improve metabolic control and reduce the risk of both short term complications (i.e. hypoglycemic events and ketoacidosis) and long term vascular complications (6).

Metabolic control close to diagnosis of the disease has been shown to be related to later metabolic control (7-10). Viswanathan et al. showed that HbA1c levels at onset might predict future metabolic control; however, the study only included 120 children with data obtained at diagnosis and at follow-up after six weeks, one, two, three and four years after diagnosis and was conducted with data from a large tertiary care centre (11). Redondo et al. studied determinants of HbA1c one year after diagnosis of T1D, in 857 patients recruited from 7 clinical centers, and found no association of HbA1c at onset and HbA1c value one year after diagnosis (12). It has recently been shown that a high mean HbA1c shortly after diagnosis (i.e. 3-15 months after onset) and during adolescence increases the risk for microvascular complications in early adulthood $(13,14)$. Hofer et al. described metabolic tracking from childhood until young adulthood, identifying pre-pubertal HbA1c as a predictor of metabolic control in young adulthood, but the influence of HbA1c at onset per se was not studied (15).

Lind et al. have recently shown an excess risk of death from any cause for adult Swedish patients with T1D; a doubled risk even with good glycaemic control, $\leq 52 \mathrm{mmol} / \mathrm{mol}$ (6.9\%), and an almost ten times higher mortality risk with a mean HbA1c above $83 \mathrm{mmol} / \mathrm{mol}(9.7$ 
$\%)$. Adults $\leq 34$ years of age had an increased risk of premature death, and diabetic ketoacidosis and hypoglycaemia contributed to $31.4 \%$ of this risk (16). It is not known how these individuals presented at onset and how their metabolic control was during childhood.

Increasing evidence indicates the importance of good glycaemic control during childhood, to avoid future morbidity and premature death. However, the importance of HbA1c at disease onset is not well studied. Present studies either include few patients or have short follow-up time and none is based on nationwide data.

The aim of this study was to investigate the metabolic and clinical pattern in children and adolescents at onset of the disease, using a population based registry, and to relate this to metabolic control and clinical factors at follow-up after three months, one, three and five years and at transition from paediatric care to adult diabetes care. This may help in identifying risk patients close to diagnosis, allowing them to be offered more targeted care and resources. 


\section{Patients and methods}

\section{The Swedish pediatric diabetes quality registry, SWEDIABKIDS}

The SWEDIABKIDS database, established in 2000, consists of outpatient data from all Swedish paediatric diabetes centres $(n=43)$. Since 2007 the registry has included data on $99 \%$ of children and adolescents with diabetes in Sweden. It includes data from onset as well as from every patient visit. According to Swedish national guidelines, each child should visit the paediatric outpatient diabetes clinic about four times per year. HbA1c and clinical parameters such as insulin regimen, weight, length, BMI, blood pressure, and status of smoking, physical activity and severe hypoglycaemia/ketoacidosis are measured and recorded online by trained nurses or physicians (17). The patients also report smoking habits and how frequently they participate in physical activity on a weekly basis. Physical activity is defined as at least 30 minutes duration and is grouped in the registry as follows: 1 - none, $2-$ less than once a week, 3 - 1-2 times per week, 4 - 3-5 times per week and 5 - every day. The Swedish national guidelines state a goal of achieving HbA1c $<57 \mathrm{mmol} / \mathrm{mol}(7.4 \%)$ for children and adolescents with diabetes (18). The Swedish National Board of Health and Welfare defines HbA1c $>72(8.7 \%)$ as high.

SWEDIABKIDS is financially supported by the Swedish Association of Local Authorities and Regions, SALAR, which represents the governmental, professional and employer-related interests of Sweden's municipalities, county councils and regions [URL:http://skl.se/english/ (accessed September 2015)]. The registry has the status of a national quality registry, and the families/patients give informed consent to be included in the register.

All laboratory methods used in Sweden are standardized through EQUALIS (External Quality Assurance in Laboratory Medicine in Sweden). Data on HbA1c are derived from capillary 
blood samples taken in connection with visits to the diabetes centre. The International Federation of Clinical Chemistry and Laboratory Medicine (IFCC) reference method is being used in Sweden, and HbA1c values are presented both as IFCC (mmol/mol) and as NGSP/DCCT (\%).

\section{Study population}

All children and adolescents diagnosed with T1D and registered in SWEDIABKIDS 20002014 were included, which renders the study population nationwide and population-based. Visits where HbA1c was not registered were not included in the analysis. 8084 patients that had an HbA1c value registered at the one-year follow-up after diagnosis were included, and of these, $26 \%$ had been transitioned to adult care in 2014 .

Data was obtained at onset, three months, one, three and five years after diagnosis and at transition. HbA1c, BMI, BMI SDS, blood pressure, $\mathrm{pH}$-value at diagnosis, physical activity, smoking, gender and retinopathy were recorded. Smoking was analysed in children 13 years of age or older and physical activity in children seven years of age or older, as these data are not registered in younger children in SWEDIABKIDS. Smoking and physical activity are not registered until the three-month follow-up after diagnosis. Retinopathy is assessed locally, i.e. through fundus photography performed by an ophthalmologist, and categorized as yes or no.

HbA1c at onset was divided into quintiles, the lowest with $\mathrm{HbA1c}<72 \mathrm{mmol} / \mathrm{mol}(8.7 \%)$ (low group) and the highest with HbA1c > $114 \mathrm{mmol} / \mathrm{mol}$ (12.6 \%) (high group). The quintiles 2-4 are defined as moderate group, HbA1c 72-114 mmol/mol (8.7 - 12.6 \%). These groups were thereafter compared with mean HbA1c at follow-up and with clinical parameters both at onset and follow-up.

\section{Statistical analysis}


SPSS $22^{\circledR}$ (SPSS Inc., Chicago, IL, USA) was used for the analyses. The statistical methods were descriptive. A student's t-test and one-way analysis of variance (ANOVA) was used, including the Bonferroni procedure. Groups were compared by crosstabs, and chi-square was used for proportions. Linear regression was used to test the relationship between HbA1c at diagnosis and at follow-up. A p-value $<0.05$, two-sided was regarded as statistically significant. Results are presented as mean \pm SD.

The study was approved by the regional ethics committee in Linköping, Sweden. 


\section{Results}

Background data on number of patients included and HbA1c values at each follow-up time are shown in table 1.

Patients in the low HbA1c group at diagnosis were younger $(\mathrm{p}<0.001)$, had higher BMI SDS ( $p<0.01)$, lower blood pressure $(\mathrm{p}<0.01)$ and higher $\mathrm{pH}$-value $(\mathrm{p}<0.01)$ compared to the high HbA1c group. The proportion of girls was higher in the high group (Table 2). This was not an effect of age at diagnosis, as girls had a mean age of $8.9 \pm 4.1$ vs. boys $9.6 \pm 4.7$ years $(\mathrm{p}<0.001)$

Children and adolescents in the high HbA1c group at diagnosis were more frequently smokers ( $\mathrm{p}<0.01)$, were less physically active $(\mathrm{p}<0.01)$, had higher BMI SDS $(\mathrm{p}<0.01)$, higher blood pressure $(\mathrm{p}<0.05)$ and higher frequency of retinopathy $(\mathrm{p}<0.03)$ at follow-up after five years than children in the low HbA1c group at diagnosis (Table 2, fig 1). For smokers at the five-year follow-up, HbA1c was $79 \pm 17 \mathrm{mmol} / \mathrm{mol}(9.4 \pm 1.6 \%) \mathrm{vs} .63 \pm 13 \mathrm{mmol} / \mathrm{mol}$ $(7.9 \pm 1.2 \%)$ for non-smokers $(\mathrm{n}=1702, \mathrm{p}<0.001)$. For children with retinopathy, after five years $\mathrm{HbA1c}$ was $71 \pm 16 \mathrm{mmol} / \mathrm{mol}(8.6 \pm 1.5 \%)$ vs. $64 \pm 13 \mathrm{mmol} / \mathrm{mol}(8.0 \pm 1.2 \%)$ for those without retinopathy $(\mathrm{n}=369, \mathrm{p}<0.01)$. Children with ketoacidosis at disease onset $(\mathrm{pH}$ < 7.30) had marginally higher HbA1c at follow-up vs. children with normal pH at onset, mean $64 \mathrm{mmol} / \mathrm{mol}(8.0 \%)$ at the five-year follow-up vs. $63 \mathrm{mmol} / \mathrm{mol}(7.9 \%)(\mathrm{p}=0.096)$, and 69 $\mathrm{mmol} / \mathrm{mol}(8.5 \%)$ at transition vs. $67 \mathrm{mmol} / \mathrm{mol}(8.3 \%)(\mathrm{p}=0.023)$.

Girls were overrepresented in the high HbA1c group at onset. $23.5 \%$ of the girls and $16.6 \%$ of the boys had HbA1c $>114 \mathrm{mmol} / \mathrm{mol}(12.6 \%)$ at diagnosis $(\mathrm{p}<0.001)$. In the low HbA1c group at diagnosis, the distribution was $18.1 \%$ girls and $20.3 \%$ boys and in the moderate HbA1c group (quintile 2-4) $58.4 \%$ girls and $63.1 \%$ boys ( $<$ 0.001). Girls had marginally 
higher HbA1c during follow-up except after three years. The difference was not significant except at transition, where girls had mean HbA1c $69 \pm 16$ mmol/mol (8.5 $\pm 1.5 \%$ \%) compared to boys $66 \pm 14 \mathrm{mmol} / \mathrm{mol}(8.2 \pm 1.3 \%)(\mathrm{p}<0.02)$.

Children in the low group at diagnosis, HbA1c $<72 \mathrm{mmol} / \mathrm{mol}$ (8.7 \%), had better metabolic control during childhood and adolescence, compared to children in the high group at diagnosis, HbA1c > $114 \mathrm{mmol} / \mathrm{mol}$ (12.6 \%). The difference was significant at every followup point except at transition (three months $\mathrm{p}<0.05$, one year $\mathrm{p}<0.05$, three years $\mathrm{p}<0.01$, five years $\mathrm{p}<0.01$, at transition n.s.). In general, HbA1c increases during follow-up (Fig 2).

When using a linear regression model, there was no predictive value between $\mathrm{HbA} 1 \mathrm{c}$ at onset and future metabolic control for the individual $\left(\mathrm{R}^{2}=0.022\right.$ at five-year follow-up, fig 3). 


\section{Discussion}

This nationwide population-based study shows that HbA1c at diagnosis affects future metabolic control during childhood and adolescence. This confirms earlier studies by Viswanathan et al. (11) and Shalitin and Phillip (10), which both had small numbers of patients and short follow-up times.

One explanation might be that families who are unaware of their children's symptoms at diagnosis are also less aware of symptoms of poor metabolic control later. The clinical difference in HbA1c is not marked at the three-month follow-up, which could be explained by residual beta-cell function during the first months, which then subsides and gives more pronounced differences at three-year and five-year follow-ups. The clinical difference in HbA1c at transition is also negligible, even though it is significant. These patients are older and may receive more input from the diabetes team and may participate more actively in their care.

However, this was only true when looking at the population divided into subgroups of different metabolic control at onset. For the individual, HbA1c at onset only had 2.2 percent predictive value for future metabolic control during childhood and adolescence. Our results are an indication that the hard work done by the diabetes team has an effect for the individual child and can counteract the effect of high HbA1c at diagnosis. It also implies that for each individual, high HbA1c at diagnosis does not per se predestine poor metabolic control in the future.

Smoking was clearly associated with high HbA1c. The same was true for a low level of physical activity. Smoking and low level of physical activity might be a marker for poor family support. Previous studies have shown that children who succeed in maintaining good 
metabolic control have families with more resources, such as better economy, increased time commitment and more knowledge of the disease, $(19,20)$. Due to legislation, SWEDIABKIDS does not allow data collection on family resources and socioeconomic status.

Girls had higher levels of HbA1c than boys, both at diagnosis and follow-up, which has already been shown by Åkesson et al. (21). It was there shown that higher HbA1c at diagnosis was correlated to a decrease in BMI and $\mathrm{pH}$, thereby presenting with more disease symptoms. The reason for this is not understood. Could there be less awareness of disease symptoms in girls than in boys at onset? The reason might also be due to the well-known hormonal differences between genders.

Children presenting with high HbA1c were older than those with low HbA1c at onset - mean age 12.6 years compared to mean age 7.6 years. The patients with high HbA1c at diagnosis continued to have poor metabolic control as a group. This is in line with a study by Clements et al., where older age at diagnosis was a predictor for deterioration in glycaemic control during the first five years after diagnosis, and they also presented with higher HbA1c values (22). This could be due to hormone- induced insulin resistance during puberty $(23,24)$. In contrast to younger children, teenagers are often more actively involved in their own treatment and may be expected to take more responsibility for their disease. It may be difficult to establish good metabolic control later during the course of disease if tight metabolic control is not achieved close to diagnosis, and adolescence is known as a problematic period when it comes to adherence to treatment and achieving glycaemic control (25-27). Taking this into account, it is important but also a challenge for the diabetes team to encourage teenagers to improved self -care and a healthy lifestyle, i.e. increased physical activity and non-smoking habits, as a way to decrease HbA1c levels in this age group. 
Other explanations for why some children present with very high HbA1c values and continue to have poor metabolic control during follow-up, no matter what efforts are made by the diabetes team, might be related to pathophysiological or genetic issues, which warrants further research.

This is a large, population-based study with a retrospective design. The data is based on registry information and relies on correct information being entered into the registry.

In summary, this study shows that having high HbA1c at diagnosis is associated with poor metabolic control during childhood on a group level, thereby in part confirming previous smaller studies, but for the individual high HbA1c cannot be used as a predictor for future metabolic control. In other words, the work done by the diabetes team the first years after diagnosis, despite age at onset, truly makes a difference, and it is important to maintain this investment in team and patients in order to prevent continuously high HbA1c and diabetic complications. Clinical characteristics such as older age and low BMI-SDS at onset, smoking and low physical activity, together with female gender can be of help in identifying which patients the diabetes team needs to focus on and provide extra support to right from the start. 


\section{Acknowledgements}

We thank The Swedish board of Health and Welfare, the Swedish Association of Local

Authorities and Regions. We thank the diabetes centres who have contributed to the study by registering data on the children and adolescents with type1 diabetes attending their diabetes centre. This study was supported by Futurum, the academy for Health and Care, Jönköping County Council. 


\section{Tables}

Table 1. Background data on number of patients and mean HbA1c at onset and follow-up.

\begin{tabular}{lcc}
\hline & $\mathrm{N}$ & HbA1c (SD) \\
\hline Onset & $7170(7170)$ & $92.8 \pm 25(10.6 \pm 2.3)$ \\
3 months & $6535(5895)$ & $48.8 \pm 10(6.6 \pm 0.9)$ \\
1 year & $8084(7170)$ & $55.0 \pm 12(7.2 \pm 1.1)$ \\
3 years & $6087(5491)$ & $61.0 \pm 13(7.7 \pm 1.2)$ \\
5 years & $4219(3839)$ & $63.4 \pm 13(8.0 \pm 1.2)$ \\
At transition & $2107(1882)$ & $67.6 \pm 15(8.3 \pm 1.4)$ \\
\hline
\end{tabular}

$\mathrm{N}\left({ }^{*}\right)$ are patients having HbA1c at diagnosis registered. HbA1c figures with parenthesis are NGSP/DCCT-values. 
Table 2. Clinical characteristics at diagnosis, and at three-month and five-year follow-ups in the three HbA1c subgroups. P-values refer to differences between the three groups in the table; quintile 1, 2-4 and 5.

\section{$\mathrm{HbA1c}$ at diagnosis}

$(\mathrm{mmol} / \mathrm{mol})$

Quintile $1(<72) \quad$ Quintile 2-4 (72-114) Quintile 5 (>114)

\begin{tabular}{lcccc} 
At diagnosis & $(\mathrm{n}=1384)$ & $(\mathrm{n}=4370)$ & $(\mathrm{n}=1416)$ & $p$-value \\
\hline Age & $7.6 \pm 4.3$ & $9.1 \pm 4.5$ & $11.6 \pm 3.3$ & $<0.001$ \\
BMI SDS & -0.03 & -0.42 & -0.84 & $<0.01$ \\
Blood pressure, syst, & & & & \\
$\mathrm{mm} / \mathrm{Hg}$ & $108 \pm 14$ & $110 \pm 14$ & $112 \pm 13$ & $<0.01$ \\
Blood pressure, diast, & & & & \\
$\mathrm{mm} /$ Hg & $64 \pm 10$ & $66 \pm 10$ & $68 \pm 11$ & $<0.05$ \\
Males/Females (\%) & $788 / 596(57 / 43)$ & $2449 / 1921(56 / 44)$ & $643 / 773(45 / 55)$ & $<0.001$ \\
$\mathrm{pH}$ & $7.38 \pm 0.06$ & $7.34 \pm 0.1$ & $7.31 \pm 0.12$ & $<0.01$ \\
\hline
\end{tabular}

3 months

\begin{tabular}{|c|c|c|c|c|}
\hline $\mathrm{HbA1c}(\mathrm{mmol} / \mathrm{mol})$ & $48.1 \pm 10$ & $48.8 \pm 10$ & $49.1 \pm 10$ & $<0.05$ \\
\hline BMI SDS & 0.65 & 0.59 & 0.71 & $<0.01$ \\
\hline \multicolumn{5}{|l|}{ Blood pressure, syst, } \\
\hline $\mathrm{mm} / \mathrm{Hg}$ & $104 \pm 11$ & $106 \pm 13$ & $107 \pm 11$ & $<0.05$ \\
\hline \multicolumn{5}{|l|}{ Blood pressure, diast, } \\
\hline $\mathrm{mm} / \mathrm{Hg}$ & $62 \pm 9$ & $63 \pm 8$ & $64 \pm 8$ & $<0.05$ \\
\hline Physical activity, mean & $3.7 \pm 1.0$ & $3.7 \pm 1.0$ & $3.5 \pm 1.0$ & $<0.01$ \\
\hline
\end{tabular}


(1=never, 5 =daily)

Smokers (\%)

Retinopathy (\%)
0

0
0.5

3.9
2.1

2.5

$<0.001$

5 years

$\mathrm{HbA1c}(\mathrm{mmol} / \mathrm{mol})$

BMI SDS

Blood pressure, syst,

$\mathrm{mm} / \mathrm{Hg}$

$110 \pm 13$

$113 \pm 12$

$65 \pm 8$

$67 \pm 8$

$68 \pm 8$

Physical activity, mean

(1=never, 5=daily)

$3.7 \pm 1.0$

$3.6 \pm 1.0$

$3.4 \pm 1.0$

$<0.01$
4.1

2.3
Smokers (\%)

2.3

4.9

7.6

$<0.01$

Retinopathy (\%)

$<0.03$ 


\section{Illustrations}

Fig 1.

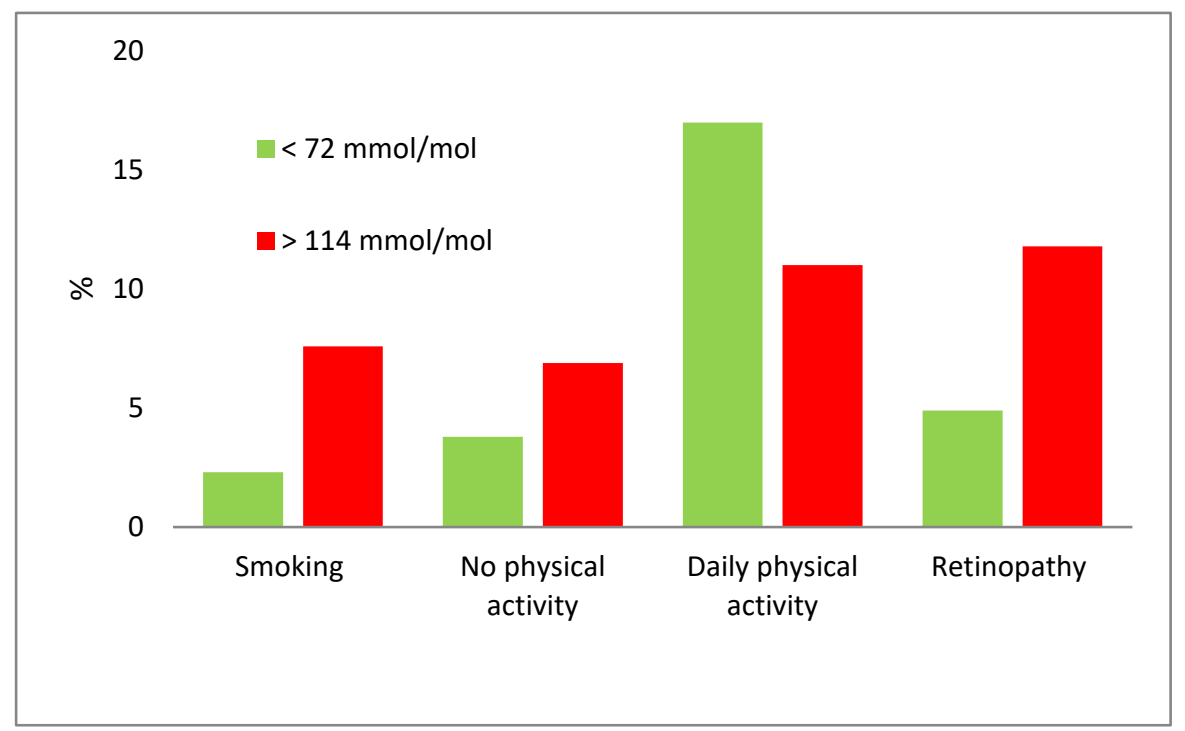


Fig 2.

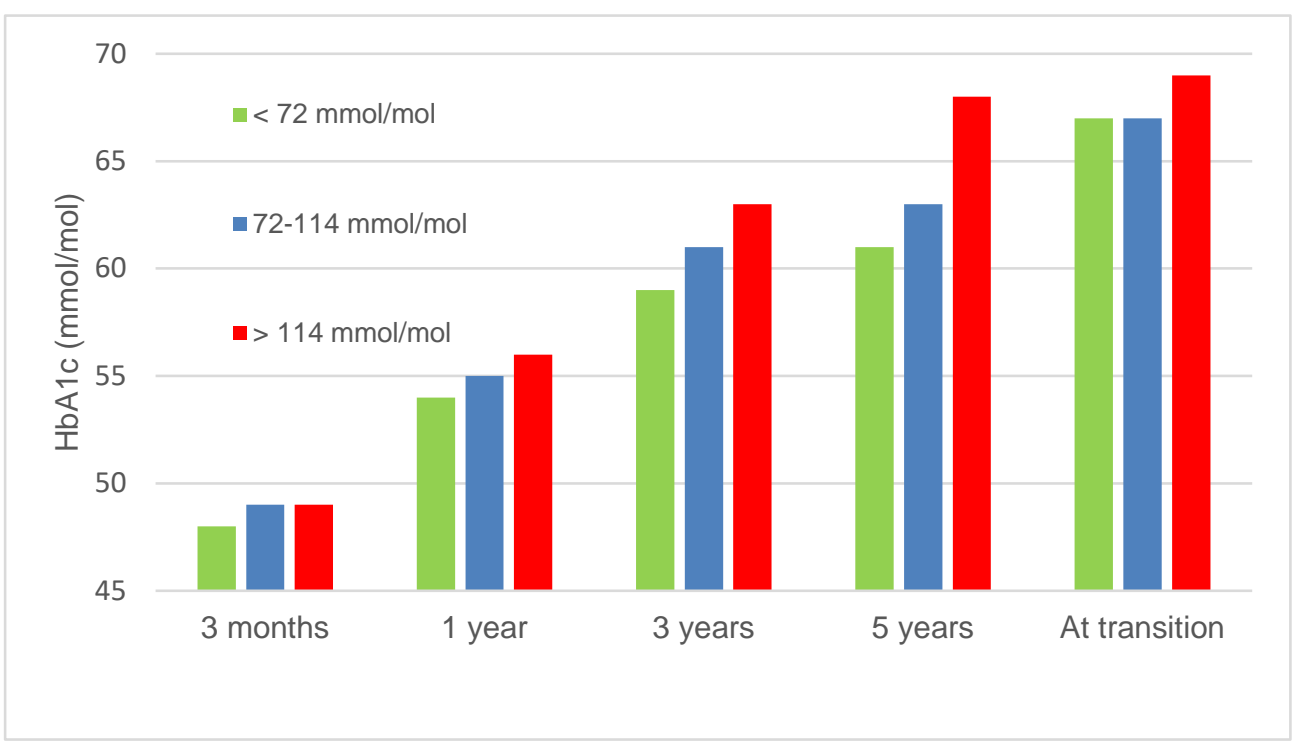


Fig 3.

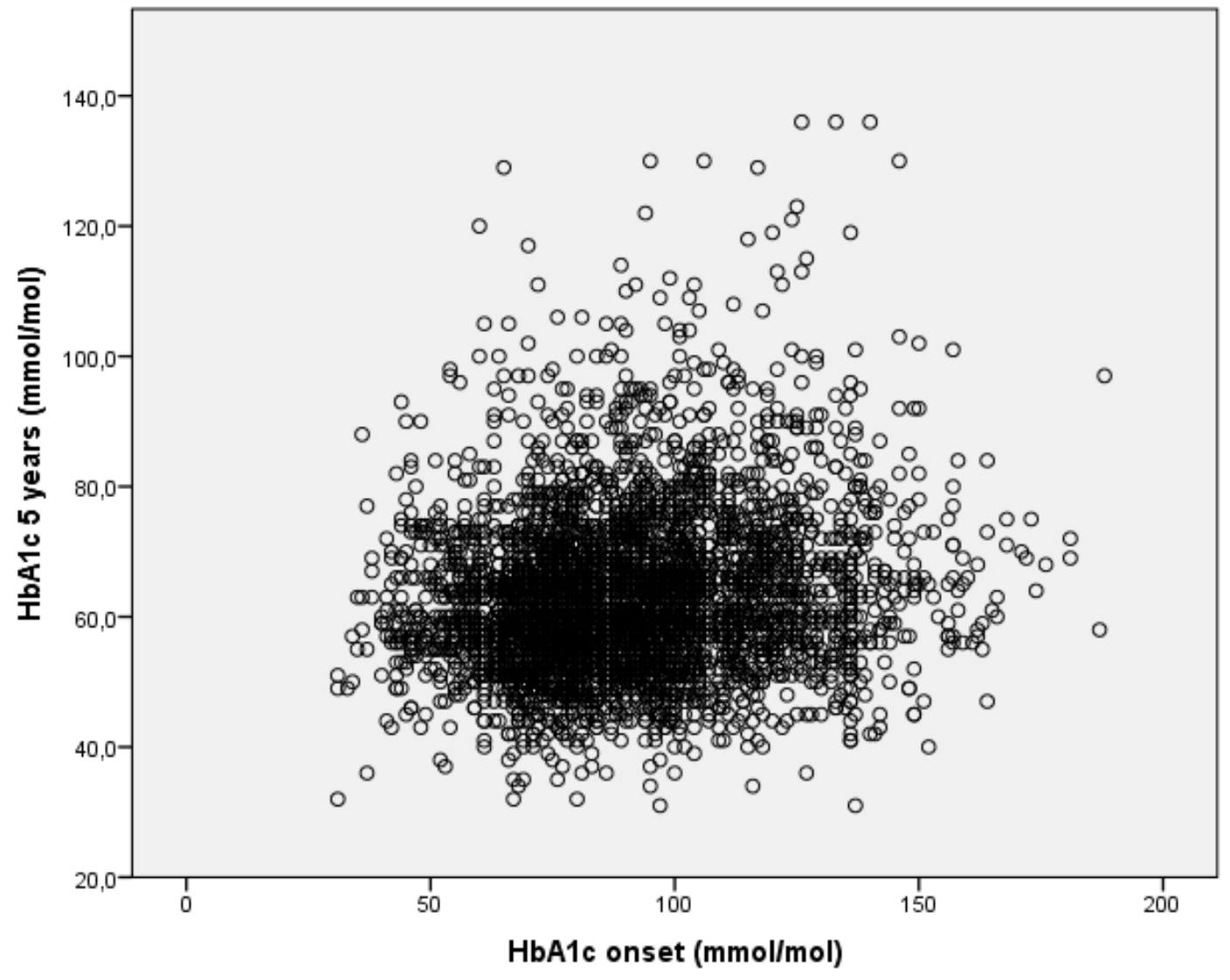




\section{Legends}

Fig 1. Smoking, physical activity and retinopathy after five years in relation to low or high HbA1c group at onset.

Fig 2. HbA1c subgroups at onset in relation to HbA1c during follow-up.

Fig 3. Linear regression between HbA1c at onset and at follow-up after five years $\left(\mathrm{R}^{2}=0.022\right)$. 


\section{References}

1. The effect of intensive treatment of diabetes on the development and progression of long-term complications in insulin-dependent diabetes mellitus. The Diabetes Control and Complications Trial Research Group. The New England journal of medicine. 1993; 329:977-86.

2. Fullerton B, Jeitler K, Seitz M, Horvath K, Berghold A, Siebenhofer A. Intensive glucose control versus conventional glucose control for type 1 diabetes mellitus. The Cochrane database of systematic reviews. 2014; 2:CD009122.

3. Nordwall M, Arnqvist HJ, Bojestig M, Ludvigsson J. Good glycemic control remains crucial in prevention of late diabetic complications--the Linkoping Diabetes Complications Study. Pediatric diabetes. 2009; 10:168-76.

4. Olsen BS, Sjolie AK, Hougaard P, Johannesen J, Marinelli K, Jacobsen BB, et al. The significance of the prepubertal diabetes duration for the development of retinopathy and nephropathy in patients with type 1 diabetes. Journal of diabetes and its complications. 2004; 18:160-4.

5. Nathan DM, Turgeon H, Regan S. Relationship between glycated haemoglobin levels and mean glucose levels over time. Diabetologia. 2007; 50:2239-44.

6. Rewers MJ, Pillay K, de Beaufort C, Craig ME, Hanas R, Acerini CL, et al. ISPAD Clinical Practice Consensus Guidelines 2014. Assessment and monitoring of glycemic control in children and adolescents with diabetes. Pediatric diabetes. 2014; 15 Suppl 20:102-14.

7. Nardi L, Zucchini S, D'Alberton F, Salardi S, Maltoni G, Bisacchi N, et al. Quality of life, psychological adjustment and metabolic control in youths with type 1 diabetes: a study with self- and parent-report questionnaires. Pediatric diabetes. 2008; 9:496-503.

8. Svensson M, Eriksson JW, Dahlquist G. Early glycemic control, age at onset, and development of microvascular complications in childhood-onset type 1 diabetes: a population-based study in northern Sweden. Diabetes care. 2004; 27:955-62.

9. Wysocki T, Lochrie A, Antal H, Buckloh LM. Youth and parent knowledge and communication about major complications of type 1 diabetes: associations with diabetes outcomes. Diabetes care. 2011; 34:1701-5.

10. Shalitin S, Phillip M. Which factors predict glycemic control in children diagnosed with type 1 diabetes before 6.5 years of age? Acta diabetologica. 2012; 49:355-62.

11. Viswanathan V, Sneeringer MR, Miller A, Eugster EA, DiMeglio LA. The utility of hemoglobin $\mathrm{A} 1 \mathrm{c}$ at diagnosis for prediction of future glycemic control in children with type 1 diabetes. Diabetes research and clinical practice. 2011; 92:65-8.

12. Redondo MJ, Connor CG, Ruedy KJ, Beck RW, Kollman C, Wood JR, et al. Pediatric Diabetes Consortium Type 1 Diabetes New Onset (NeOn) Study: factors associated with HbA1c levels one year after diagnosis. Pediatric diabetes. 2014; 15:294-302.

13. Samuelsson U, Steineck I, Gubbjornsdottir S. A high mean-HbA1c value 3-15 months after diagnosis of type 1 diabetes in childhood is related to metabolic control, macroalbuminuria, and retinopathy in early adulthood--a pilot study using two nation-wide population based quality registries. Pediatric diabetes. 2014; 15:229-35.

14. Anderzen J, Samuelsson U, Gudbjornsdottir S, Hanberger L, Akesson K. Teenagers with poor metabolic control already have a higher risk of microvascular complications as young adults. Journal of diabetes and its complications. 2015.

15. Hofer SE, Raile K, Frohlich-Reiterer E, Kapellen T, Dost A, Rosenbauer J, et al. Tracking of metabolic control from childhood to young adulthood in type 1 diabetes. The Journal of pediatrics. 2014; 165:956-61.e1-2.

16. Lind M, Svensson AM, Kosiborod M, Gudbjornsdottir S, Pivodic A, Wedel H, et al. Glycemic control and excess mortality in type 1 diabetes. The New England journal of medicine. 2014; 371:1972-82. 
18. Sjöblad S. Barn- och ungdomsdiabetes. 2 Ed. Studentlitteratur AB2008.

19. Gallegos-Macias AR, Macias SR, Kaufman E, Skipper B, Kalishman N. Relationship between glycemic control, ethnicity and socioeconomic status in Hispanic and white non-Hispanic youths with type 1 diabetes mellitus. Pediatric diabetes. 2003; 4:19-23.

20. Haugstvedt A, Wentzel-Larsen T, Rokne B, Graue M. Psychosocial family factors and glycemic control among children aged 1-15 years with type 1 diabetes: a population-based survey. BMC pediatrics. 2011; 11:118.

21. Akesson K, Hanberger L, Samuelsson U. The influence of age, gender, insulin dose, $\mathrm{BMI}$, and blood pressure on metabolic control in young patients with type 1 diabetes. Pediatric diabetes. 2014.

22. Clements MA, Lind M, Raman S, Patton SR, Lipska KJ, Fridlington AG, et al. Age at diagnosis predicts deterioration in glycaemic control among children and adolescents with type 1 diabetes. BMJ open diabetes research \& care. 2014; 2:e000039.

23. Szadkowska A, Pietrzak I, Mianowska B, Bodalska-Lipinska J, Keenan HA, ToporowskaKowalska $E$, et al. Insulin sensitivity in Type 1 diabetic children and adolescents. Diabetic medicine : a journal of the British Diabetic Association. 2008; 25:282-8.

24. Acerini CL, Williams RM, Dunger DB. Metabolic impact of puberty on the course of type 1 diabetes. Diabetes \& metabolism. 2001; 27:S19-25.

25. Helgeson VS, Siminerio L, Escobar O, Becker D. Predictors of metabolic control among adolescents with diabetes: a 4-year longitudinal study. Journal of pediatric psychology. 2009; 34:25470.

26. King PS, Berg CA, Butner J, Drew LM, Foster C, Donaldson D, et al. Longitudinal trajectories of metabolic control across adolescence: associations with parental involvement, adolescents' psychosocial maturity, and health care utilization. The Journal of adolescent health : official publication of the Society for Adolescent Medicine. 2012; 50:491-6.

27. Helgeson VS, Snyder PR, Seltman H, Escobar O, Becker D, Siminerio L. Brief report: trajectories of glycemic control over early to middle adolescence. Journal of pediatric psychology. 2010; 35:1161-7. 